\title{
Model Pengembangan Bisnis BUMDes Berdasarkan Pendekatan Sharing economy dan Gig economy
}

\author{
Jaka Sudewa ${ }^{1)}$, Mohammad Fahreza ${ }^{2}$ \\ Institut Manajemen Koperasi Indonesia ${ }^{1), 2)}$ \\ jakasudewa@ikopin.ac.id \\ mfahreza@ikopin.ac.id
}

\begin{abstract}
ABSTRAK
Dalam upaya mendorong pelaku UMKM khususnya BUMDes Bhakti utama desa Cilembu, maka perlu dikembangkan suatu model bisnis baru yaitu dengan memanfaatkan peluang dengan menerapkan ekonomi digital agar kegiatan usaha BUMDes dapat beroperasi dengan baik serta dapat mengikuti perkembangan bisnis, sehingga tujuan didirikannya BUMDes dapat tercapai yaitu meningkatkan pelayanan kepada masyarakat dan memberdayakan desa sebagai wilayah yang otonom berkenaan dengan usaha-usaha produktif serta meningkatkan kemandirian dan kapasitas desa dalam penguatan ekonomi. Penelitian ini bertujuan untuk mengetahui potensi dan hambatan bisnis BUMDes Bhakti Utama, mengetahui upaya BUMDes Bhakti Utama Cilembu dalam menghidupkan kembali bisnis BUMDes yang saat ini vakum serta untuk merumuskan model sharing economy and Gig economy sehingga ditemukan model bisnis yang tepat bagi BUMDes khususnya BUMDes Bhakti Utama yang dapat dikembangkan dan beroperasi di Desa Cilembu sehingga memiliki strategi pengembangan bisnis yang sesuai dengan kondisi saat ini. Dengan demikian, kajian ini memiliki kontribusi, baik dalam pengembangan teori maupun dalam praktek bisnis sharing economy dan Gig economy dalam upaya pemberdayaan ekonomi desa. Metode yang digunakan dalam penelitian ini adalah analisis deskriptif kualitatif, yang disajikan dalam bentuk gambar, tabel dan uraian. Metode analisis deskriptif ini diolah berdasarkan elemen-elemen Business Model Canvas dan dilakukan analisis potensi dan hambatan bisnis-bisnis kemudian dianalisis berdasarkan pendekatan sharing economy and Gig economy untuk mendapatkan model sharing economy and gig economy. Selanjutnya, dilakukan analisis SWOT dan PESTEL untuk menilai sejauh apa model bisnis baru dapat digunakan sehingga dapat dirumuskan alternatif strategi/ upaya yang dapat dilakukan.
\end{abstract}

Kata Kunci: BUMDes, Sharing Economy, Gig Economy, Business Model

\begin{abstract}
In an effort to encourage MSMEs, especially BUMDes Bhakti, the main village of Cilembu, it is necessary to develop a new business model, namely by utilizing opportunities by implementing the digital economy so that BUMDes business activities can operate properly and can follow business developments, so that the purpose of bumdes can be achieved, namely improving services to the community and empowering villages as autonomous regions with regard to productive efforts and improving business. kemandirian and village capacity in strengthening the economy. This research aims to find out the potential and business barriers of BUMDes Bhakti Utama, knowing the efforts of BUMDes Bhakti Utama Cilembu in reviving bumdes business that is currently vacuum and to formulate a sharing economy and Gig economy model so that the right business model is found for BUMDes, especially BUMDes Bhakti Utama that can be developed and operate in Cilembu Village so that it has a business development strategy that is in accordance with current conditions. Thus, this study has a contribution, both in the development of theory and in the business practices of sharing economy and Gig economy in efforts to empower the village economy. The method used in this study is qualitative descriptive analysis, which is presented in the form of drawings, tables and descriptions. This descriptive analysis method is processed based on elements of the Business Model Canvas and conducted an analysis of the potential and obstacles of businesses and then analyzed based on the sharing economy and Gig economy approach to get the sharing economy and Gig economy model. Furthermore, SWOT and PESTEL analysis is carried out to assess the extent to which new business models can be used so that alternative strategies / efforts can be formulated.
\end{abstract}

Keywords: BUMDes, Sharing Economy, Gig Economy, Business Model 


\section{PENDAHULUAN}

Dalam rangka mengakomodasi potensi desa dan pemenuhan kesejahteraan warga desa, pemerintah memberikan dukungan besar agar desa memiliki badan usaha yang mampu mengembangkan dan menggerakkan perekonomian lokal. Berdasarkan data Bidang 7 TPP Pusat tahun 2019 dari total 47.610 BUMDes yang ada di Indonesia, masalah pada umumnya dialami oleh BUMDes berdasarkan data dari pendampingan desa bahwa sebanyak 40.997 BUMDes teridentifikasi memiliki permasalahan yang bervariasi, yaitu permasalahan kelembagaan, manajemen, sumber daya manusia dan kegiatan usaha atau produksi. Permasalahan lain juga terkait dengan pelayanan dan pemasaran. Hingga sampai saat ini, berbagai sumber berita menyebut bahwa sebagian besar BUMDes masih sebatas berdiri dan belum memiliki aktivitas bisnis yang menghasilkan omzet yang tinggi.

Permasalahan di atas juga dialami oleh Badan Usaha Milik Desa Cilembu dengan nama BUMDes Bhakti Utama didirikan pada tahun 2016. Dalam menjalankan bisnisnya BUMDes Bhakti Utama saat ini dinyatakan vakum karena beberapa masalah yang belum membuahkan solusi yang tepat padahal BUMDes Bhakti Utama tidak kesulitan untuk modal dan tempat usaha dalam menjalankan bisnis. Tercatat hingga saat ini BUMDes memiliki aset senilai Rp. 100.000.000,- dengan aset berupa ruko sebanyak 3 bangunan. Pengelolaan BUMDes bisa dikatakan sulit karena adanya masalah seperti keterbatasan Sumber Daya Manusia, manajemen usaha belum tepat, masalah pengaturan organisasi, belum menemukan dan mengembangkan potensi desa, masalah promosi dan lain-lain.

Berdasarkan masalah tersebut, BUMDes memerlukan model Bisnis. Model bisnis dapat didefinisikan sebagai metode yang digunakan oleh perusahaan untuk menghasilkan uang di lingkungan bisnis dimana perusahaan beroperasi (Wheelen dan Hunger, 2010). Dalam menilai dan memahami kondisi Desa Cilembu untuk bisnis BUMDes Bhakti Utama, maka konsep bisnis model yang ditawarkan adalah melalui pendekatan sharing economy dan gig economy. Sharing economy menciptakan sebuah solusi bagi mereka yang tidak memiliki pekerjaan atau memiliki pekerjaan dengan gaji yang tidak mencukupi kebutuhan dengan "bergabung" ke dalamnya. Serta sharing economy juga merupakan aktivitas ekonomi peer to peer atau person to person yang difasilitasi oleh platform digital dalam praktik bertransaksinya. Kemudian dari sharing economy ini lahirlah sebuah budaya kerja yang dinamakan gig economy. Gig economy merupakan pelaksanaan pekerjaan dengan koneksi ke pelanggan dan klien melalui platform dari sharing economy dimana Gig economy memiliki karakteristik yaitu karyawan yang bekerja sesuai pada pola kerja yang fleksibel berdasarkan permintaan layanan, bekerja ditempat sendiri/rumah kemudian tugas yang dilakukan melalui platform online (ecommerce) baik dengan karyawan atau pemilik modal serta konsumen.

Dengan sharing economy, BUMDes Bhakti Utama Cilembu dapat menjadi penghubung, advertising, promosi dan pengganti jalur distribusi dari pemilik modal/ perusahaan dan menerima bagi hasil dari apa yang masyarakat lakukan. Menjadi pebisnis tanpa harus memiliki pengalaman, modal, pabrik, gudang, kantor, sewa tempat untuk menjalankan bisnis. Walaupun masyarakat memiliki pekerjaan tetap, dengan Gig economy masyarakat dapat tetap menjadi SDM yang bekerja di BUMDes Bhakti Utama Cilembu melalui aktivitas sharing economy dan pemanfaatkan platform ekonomi digital dalam praktiknya sehingga diharapkan BUMDes Bhakti Utama dapat meningkatkan pemberdayaan perekonomian desa sehingga masyarakat desa Cilembu lebih sejahtera. Oleh karena itu, BUMDes membutuhkan model bisnis untuk mendapatkan strategi yang tepat dalam melakukan pengembangan bisnis yang sesuai.

Metode Penelitian

Penelitian ini dilakukan di BUMDES Bhakti Utama, Desa Cilembu Kecamatan Pamulihan Kabupaten Sumedang. Pemilihan lokasi dilakukan secara sengaja (purposive) dengan pertimbangan lokasi tersebut memerlukan pengembangan pada model bisnisnya karena beberapa hal, salah satunya adalah terdeteksinya bisnis yang vakum sedangkan potensi desa dinilai sangat baik. Teknik sampling yang digunakan oleh peneliti adalah purposive sampling dengan menentukan kelompok peserta yang menjadi informan menurut kriteria yang relevan dengan masalah penelitian tertentu. Adapun kriterianya adalah 1) Pengurus BUMDes, 2) Masyarakat yang berprofesi sebagai petani atau memiliki bisnis sendiri 
(UMKM), dan 3) Masyarakat desa Cilembu yang merupakan golongan angkatan kerja.

Metode yang digunakan dalam penelitian ini adalah analisis deskriptif kualitatif, yang disajikan dalam bentuk gambar, tabel dan uraian. Metode analisis deskriptif ini diolah berdasarkan elemen-elemen Business Model Canvas dan dilakukan analisis potensi dan hambatan bisnis-bisnis kemudian

\section{METODE PENELITIAN}

Metode yang digunakan dalam penelitian ini adalah analisis deskriptif kualitatif, yang disajikan dalam bentuk gambar, tabel dan uraian. Metode analisis deskriptif ini diolah berdasarkan elemen-elemen Business Model Canvas dan dilakukan analisis potensi dan hambatan bisnis-bisnis kemudian dianalisis berdasarkan pendekatan sharing economy and Gig economy untuk mendapatkan model sharing economy and Gig economy. Selanjutnya, dilakukan analisis SWOT dan PESTEL untuk menilai sejauh apa model bisnis baru dapat digunakan sehingga dapat dirumuskan alternatif strategi/ upaya yang dapat dilakukan.

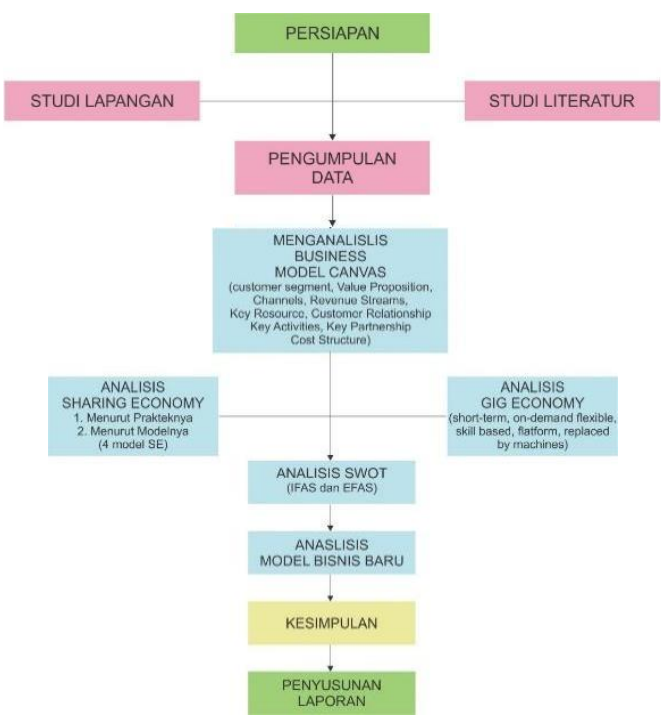

\section{HASIL DAN PEMBAHASAN}

Badan Usaha Milik Desa (BUMDes) Cilembu yang kemudian diberi nama BUMDes Bhakti Utama didirikan pada tahun 2016. Pengurus diangkat pada akhir tahun 2017 berdasarkan Surat Keputusan dianalisis berdasarkan pendekatan sharing economy and Gig economy untuk mendapatkan model sharing economy and Gig economy. Selanjutnya, dilakukan analisis SWOT dan PESTEL untuk menilai sejauh apa model bisnis baru dapat digunakan sehingga dapat dirumuskan alternatif strategi/ upaya yang dapat dilakukan.

Kepala Desa Cilembu Nomor: 141/Kep.26/Ds /2018 tanggal 25 Oktober 2018 dan memiliki kegiatan usaha yang sedang dikembangkan oleh BUMDes Bhakti Utama saat ini namun akhirnya vakum karena tidak dapat beradaptasi dengan kondisi sekarang diuraikan pada tabel sebagai berikut:

\begin{tabular}{|c|c|c|}
\hline No & Jenis Usaha & Deskripsi \\
\hline 1 & $\begin{array}{l}\text { Usaha } \\
\text { peternakan } \\
\text { kambing }\end{array}$ & $\begin{array}{l}\text { Menjual kebutuhan pupuk } \\
\text { kompos (kandang) untuk } \\
\text { kebutuhan pertanian } \\
\text { masyarakat }\end{array}$ \\
\hline 2 & $\begin{array}{l}\text { Usaha } \\
\text { perdagangan } \\
\text { umum }\end{array}$ & $\begin{array}{l}\text { Perdagangan umum yang } \\
\text { dijalankan adalah Menjual } \\
\text { ATK,fotocopy, Jual Produk } \\
\text { olahan Ubi Cilembu (Ubi } \\
\text { Bakar, kue basah, minuman, } \\
\text { snack, dsb) dan Pelayanan } \\
\text { Pembayaran PBB Secara } \\
\text { Online, agar mempermudah } \\
\text { akses Pelayanan kepada } \\
\text { Masyarakat Desa Cilembu. }\end{array}$ \\
\hline 3 & $\begin{array}{l}\text { Usaha Jasa } \\
\text { Sewa }\end{array}$ & Jasa sewa 3 unit Ruko \\
\hline \multicolumn{3}{|c|}{$\begin{array}{l}\text { Dengan dimilikinya potensi desa seperti yang } \\
\text { digambarkan sebelumnya, pemerintah desa memiliki } \\
\text { proyeksi untuk memberdayakan ekonomi masyarakat } \\
\text { desa melalui pengembangan bisnis usaha yang } \\
\text { kemudian akan dikelola oleh BUMDes. Rencana } \\
\text { usaha bisnis itu adalah: } \\
\text { 1. Transportasi (mobil wara wiri dan ojek online } \\
\text { yang dikelola BUMDes untuk memudahkan } \\
\text { konsumen dalam bertransaksi di BUMDes Bhakti } \\
\text { Utama Cilembu) }\end{array}$} \\
\hline \multicolumn{3}{|c|}{$\begin{array}{l}\text { 2. Klinik Ubi Cilembu (Menyediakan kebutuhan } \\
\text { bahan dasar pembudidayaan ubi Cilembu dan } \\
\text { menampung berbagai jenis olahan produk } \\
\text { berbahan dasar Ubi Cilembu) }\end{array}$} \\
\hline \multicolumn{3}{|c|}{$\begin{array}{l}\text { Market modern (menampung produk unggulan desa } \\
\text { yang pada umumnya merupakan sayuran, umbi- } \\
\text { umbian dan tanaman obat serta produk sembako } \\
\text { kebutuhan masyarakat desa Cilembu). }\end{array}$} \\
\hline
\end{tabular}


Analisis potensi dan hambatan usaha BUMDes dalam Business Model Canvas (BMC)

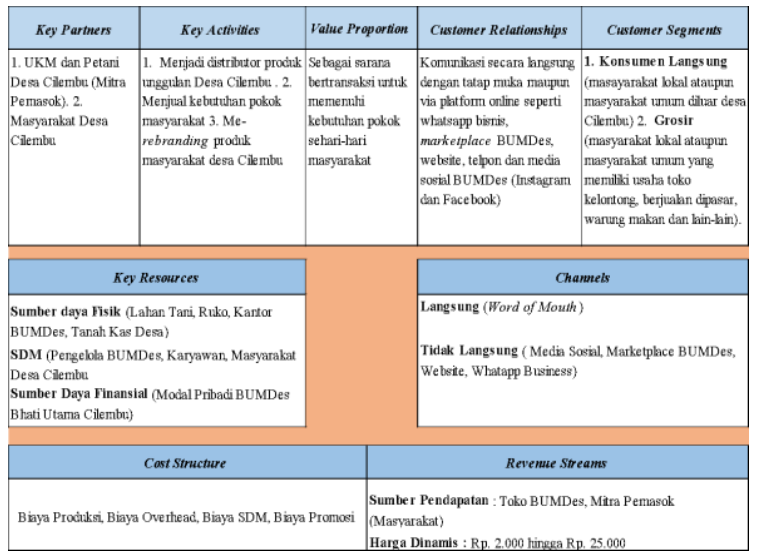

Analisis Sharing economy and Gig economy bisnis BUMDes Bhakti Utama Cilembu

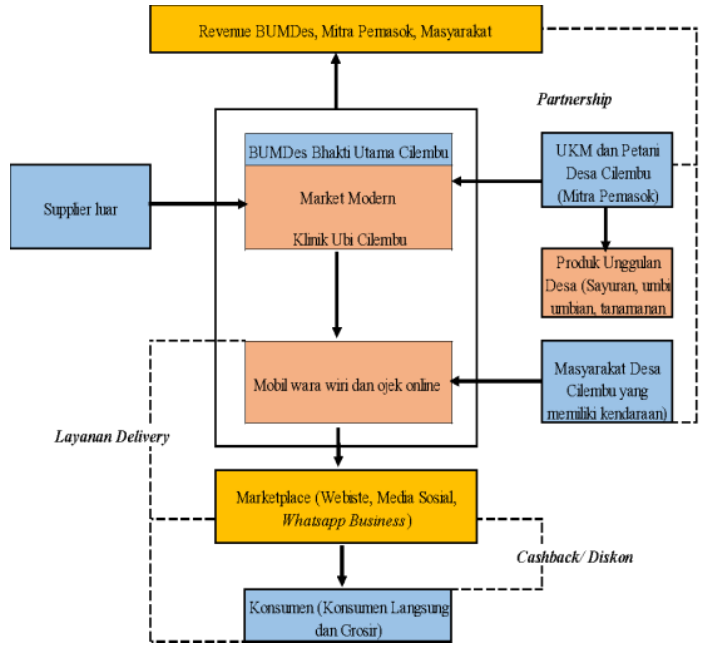

Berdasarkan analisis diatas pada praktiknya BUMDes Bhakti Utama Cilembu dapat menerapkan lima praktik sharing economy dalam mengembangkan rencana bisnisnya serta menjalankan strategi bisnis barunya. Sedangkan berdasarkan modelnya (Ioanna Constantiou et.al (2017)) sharing economy yang dapat diterapkan oleh BUMDes Bhakti Utama Cilembu adalah model Franchisee dan Chaperone.

\section{Model Sharing economy : Franchiser}

Franchisee adalah model dimana pemilik platform memiliki kontrol dan otoritas mutlak atas seluruh layanan, termasuk kekuatan untuk secara sepihak menentukan harga untuk layanan dan untuk mengubah algoritma yang digunakan untuk menghitung harga, (Ioanna, et. al, 2017). Secara sederhana, model Franchisee memiliki karakteristik di mana pemilik platform mengontrol berbagai aspek dalam layanan termasuk harga dan layanan standar. Dalam hal ini, BUMDes Bhakti Utama Cilembu menyediakan marketplace baik melalui aplikasi atau media sosial sebagai media untuk menghubungkan BUMDes- Mitra Pemasok (Petani/UKM), Masyarakat- konsumen dalam bertransaksi. Dimana harga layanan ditentukan oleh BUMDes sebagai bentuk pengendalian dan presentasi bagi hasil dengan mitra dan juga bentuk diskon dan cashback untuk konsumen ditentukan sepenuhnya oleh BUMDes. Pada praktik usaha BUMDes Bhakti Utama Cilembu model ini dapat diterapkan pada unit bisnis Market Modern dan Klinik Ubi Cilembu.

\section{Model Sharing economy : Chaperone}

Chaperone merupakan model dimana peran pemilik platform sebagai pengawas atas peserta platform dan pasar. Chaperone melakukan kontrol longgar atas peserta platform dan bertujuan untuk mengatur usaha mereka. Platform Chaperone memotivasi persaingan tinggi di antara peserta dari sisi persediaan (Ioanna, et.al, 2017). Model Chaperone menetapkan harga dan layanan standard. Dengan demikian, tingkat persaingan antar peserta menjadi tinggi. Dalam hal ini, BUMDes Bhakti Utama melalui aplikasi menyediakan unit usaha transportasi yang menghubungkan BUMDes- Mitra Masyarakat Desa Cilembu- konsumen dengan layanan jasa transportasi. BUMDes memfasilitasi konsumen dengan jasa delivery order dan masyarakat yang membutuhkan tambahan pendapatan dengan memanfaatkan aset kendaraan mereka untuk diberdayagunakan. Masyarakat mitra yang menerima order paling banyak akan mendapatkan reward/ revenue lebih tinggi pada model ini praktik Gig economy diterapkan.

Robertson (2017) menjelaskan bahwa Gig economy merupakan pekerjaan yang bersifat sementara, berjangka waktu tetap, musiman, berbasis proyek, paruh waktu, kontrak tanpa minimal jam kerja, kontrak kasual, agen, freelance, perifer (peripheral) atau pekerjaan yang tidak menerima tunjangan, kontingen (pekerjaan non permanen yang dibayar per kasus), eksternal, non-standar, tidak tipikal, berbasis platform, outsource, subkontrak, informal, tidak dideklarasikan, tidak aman, marjinal atau genting (pekerjaan yang terancam akibat kondisi keuangan).

\section{Matriks SWOT}


Tahap ini menghasilkan matriks SWOT yang berisi rumusan alternatif strategi SO, WO, ST, dan WT. Dalam penyusunan strategi tersebut dilakukan pencocokan unsur kekuatan-kelemahan dengan peluang-ancaman yang ada pada elemen Business Model Canvas. Unsur-unsur kekuatan, kelemahan peluang serta ancaman yang merupakan isu-isu strategis yang dipilah dan dirangkum dari hasil identifikasi lalu dimasukan ke dalam matriks SWOT.

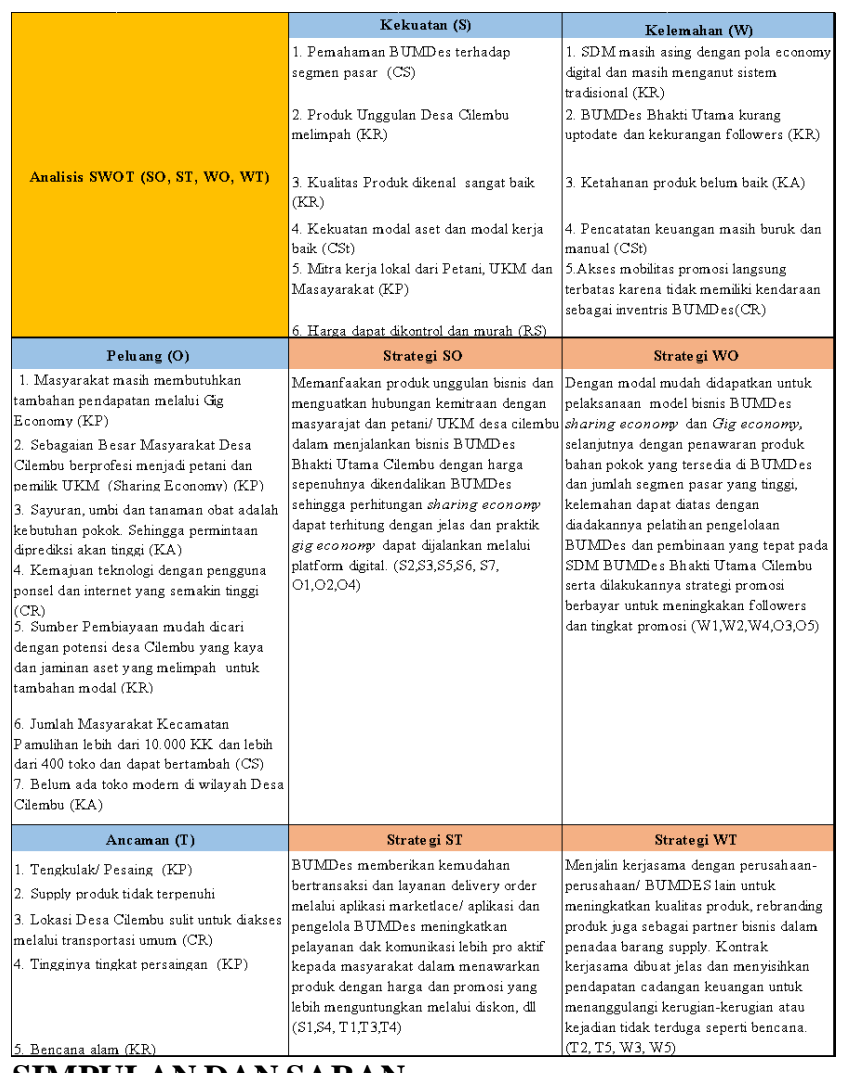

SIMPULAN DAN SARAN

Berdasarkan hasil identifikasi elemen Business Model Canvas, BUMDes Bhakti Utama Cilembu untuk rencana bisnis baru telah teridentifikasi potensi dan hambatan dalam menjalankan model bisnis baru. Secara keseluruhan, bisnis yang dijalankan BUMDes Bhakti Utama Cilembu telah memenuhi kesembilan elemen dalam Business Model Canvas, namun diperlukannya pembaharuan strategi pada model bisnisnya karena sumber daya yang melimpah di desa Cilembu belum dimanfaatkan secara optimal dan SDM pengelola perlu ditingkatkan mengingat faktor kevakuman bisnis BUMDes sebelumnya karena kurangnya manajerial dari pengelola.
BUMDes Bhakti Utama Cilembu dapat menerapkan lima praktik sharing economy dalam mengembangkan rencana bisnisnya serta menjalankan strategi bisnis barunya. Sedangkan berdasarkan modelnya (Ioanna Constantiou et.al (2017)) sharing economy yang dapat diterapkan oleh BUMDes Bhakti Utama Cilembu adalah model Franchisee dan Chaperone. Sedangkan dalam analisis Gig economy model bisnis baru memenuhi 6 karakteristik Gig economy sehingga dapat menjawab kebutuhan masyarakat dalam meningkatkan kesejahteraan masyarakat desa Cilembu.

Hasil pemetaan Business Model Canvas dievaluasi dengan pemetaan analisis SWOT dan PESTEL dan menunjukan bahwa model bisnis sharing economy dan Gig economy yang dijalankan masih memiliki beberapa kelemahan seperti sistem manajemen yang belum optimal, pemasaran dan sumber daya. Maka untuk menyempurnakan model bisnis yang ada diperlukan alternatif strategi yang digunakan seperti mengikuti pelatihan dan pendampingan Bisnis BUMDes, meningkatkan hubungan kerjasama dengan pihak luar, meningkatkan promosi, pelayanan dll.

\section{DAFTAR PUSTAKA}

https://www.setneg.go.id/baca/index/ekonomi_digital the new face of indonesias economy

Katalog,8101004. Statistik E-Commerce 2019. 2020. Badan Pusat Statistik.

Peraturan Desa Cilembu Nomor 141/03/HUK.DES/82 . 1982. Cilembu.

[PERMEN] Peraturan Menteri. 2015. Peraturan Menteri Desa, Pembangunan Daerah Tertinggal, Dan Transmigrasi Republik Indonesia nomor 4 Tahun 2015 tentang Pendirian, Pengurusan Dan Pengelolaan, Dan Pembubaran. Badan Usaha Milik Desa. Jakarta (ID): KEMENDES PDTT

Peraturan Bupati Sumedang Nomor 22 Tahun 2018. Petunjuk Teknis Pendirian, Pengelolaan Dan Pembubaran Badan Usaha Milik Desa.

Don Tapscott, The Digital Economic - Rethinking Promise and Peril in the Age of Networked Intelligence, (2015), McGraw-Hill Educations

Dahlman et al. 2016. Harnessing the digital economy for developing countries. OECD Development Centre Working Papers 334, OECD Publishing. DOI: $10.1787 / 4 a d f f b 24-e n$. 
352 Coopetition, Vol XII, Nomor 3, November 2021

(E-ISSN : 2615-4978, P-ISSN : 2086-4620)

Oecd. 2015. 'Digital Economy Outlook 2015'. Paris: oecd Pais I, Provasi G (2015) 'Sharing economy: Rustrum, C., Stempinski, G., \& Liss, A (2014). It's a shareable life: A practical guide on sharing life: Crowdsourced Self-Publishing.

Schor, J. B. (2015). Getting sharing right. Contexts, 14(1), 14-15. . [diakses pada : 1 Maret 2020]. doi: $10.1177 / 1536504214567860$

Bachdar, S. (2017, 30 November). Gig economy dan masa depan pekerja kantoran. Diakses pada 28 Februari 2020. http://marketeers.com/gigeconomy-dan-masa-depan-pekerja-kantoran/ (http://marketeers.com/gig-economy-dan-masadepan-pekerja-kantoran/).

Stewart, A. and Stanford, J. 2017. Regulating work in the gig economy: What are the options?. The Economic and Labour Relations Review. [Online]. 28(3), pp.420-437. [Accessed 15 Nov. 2017]. Available at: http://0journals.sagepub.com.wam.leeds.ac.uk

Roberston, P. (2017, 23 Oktober). Bagaimana 'Gig economy menciptakan ketidakpastian kerja. $\begin{array}{llll}\text { Diakses } & 28 & \text { Februari } & 2020 .\end{array}$ https://www.bbc.com/indonesia/vert-cap41679547

Nasutions S (2003). Metode Research. Jakarta: Penerbit Bumi Aksara.

PPM Manajemen. 2012. Business Model Canvas, Penerapan di Indonesia. Jakarta (ID). PPM Manajemen.

Rangkuti F. 2013. Analisis SWOT Teknik Membedah Kasus Bisnis: Cara Perhitungan Bobot, Rating, dan OCAI. Jakarta(ID): Gramedia Pustaka Utama. 